\title{
Thermodynamic Functions of Element 105 in Neutral and Ionized States
}

\author{
V. Pershina* and B. Fricke \\ Theoretical Physics Department, University of Kassel, 3500 Kassel, Germany \\ G. V. Ionova \\ Institute of Physical Chemistry, Russian Academy of Sciences, Moscow Leninski pr. 31, \\ 117915 Moscow, Russia
}

\section{E. Johnson}

Chemistry Division, Oak Ridge National Laboratory, Oak Ridge, Tennessee 37831-6375

Received: September 16, $1993^{\circ}$

\begin{abstract}
The basic thermodynamic functions, the entropy, free energy, and enthalpy, for element 105 (hahnium) in electronic configurations $\mathrm{d}^{3} \mathrm{~s}^{2}, \mathrm{~d}^{3} \mathrm{sp}$, and $\mathrm{d}^{4} \mathrm{~s}^{1}$ and for its +5 ionized state $\left(5 \mathrm{f}^{14}\right)$ have been calculated as a function of temperature. The data are based on the results of the calculations of the corresponding electronic states of element 105 using the multiconfiguration Dirac-Fock method.
\end{abstract}

\section{Introduction}

During recent years there has been a considerably growing interest in the physics and chemistry of the transactinide elements. Elements 104 and 105 and their halides have been studied both experimentally ${ }^{1-4}$ and theoretically. ${ }^{5-7}$ An extensively used method for experimental investigations of the properties of these elements is thermal gas chromatography. With this technique, data on the volatility of element 104 in comparison with its analogs, $\mathrm{Zr}$ and $\mathrm{Hf}$, have been obtained ${ }^{3}$ and the volatility of element 103 as a possible analog of $\mathrm{Tl}$ has been investigated. ${ }^{8}$ The gas chromatography has been applied as well to the investigation ${ }^{1-4}$ of the volatility of chlorides and bromides of elements 104 and 105 along with their analogs, $\mathrm{Zr} / \mathrm{Hf}$ and $\mathrm{Nb} / \mathrm{Ta}$, respectively.

An important aspect of the study was the investigation of the physicochemical properties of the heavy elements as a function of electronic configuration. A number of experiments ${ }^{8,9}$ were carried out to study the volatility of the elements depending on their electronic configurations, and theoretical estimations of the sublimation enthalpy of element 104 as a function of electronic configuration have been done in ref 10 using some correlations.

Estimations of the sublimation enthalpy for transactinide elements are of importance for the gas chromatography experiments. Besides, the more complete study of the physics and chemistry of the transactinide elements should include the knowledge of their thermodynamic functions, especially as a function of temperature. From the thermodynamic data it is possible to predict the chemical behavior.

The calculation of thermodynamic data, when no experimental data exist, is possible using spectroscopic levels of the gaseous atoms. Provided the latter are not known from experiment, they can be calculated using relativistic atomic codes. Thus, in this work we present the basic thermodynamic functions, $S, G$, and $H$, for element 105 , in different electronic configurations as a function of temperature, which were calculated using the energy levels obtained from the multiconfiguration Dirac-Fock (MCDF) calculations. These calculations were performed for the groundstate electronic configuration of element $105 \mathrm{~d}^{3} \mathrm{~s}^{2}\left({ }^{4} \mathrm{~F}\right)$, as well as for the excited-state electronic configurations, $\mathrm{d}^{3} \mathrm{sp}\left({ }^{6} \mathrm{G}\right)$ and $d^{4} s\left({ }^{6} D\right)$. The sublimation enthalpy of the metallic hahnium has been estimated using the MCDF atomic data.

\footnotetext{
- Abstract published in Advance ACS Abstracts, January 1, 1994.
}

TABLE 1: Calculated Relative Energy Eigenvalues for the Lowest Energy State That Is Dominated by the $d^{3} s^{2}\left({ }^{4} F\right)$ Configuration as a Function of Total Angular Momentum $J$ for $\mathrm{V}, \mathrm{Nb}, \mathrm{Ta}$, and $\mathrm{Ha}$

\begin{tabular}{|c|c|c|c|c|}
\hline \multirow[b]{2}{*}{ element } & \multirow{2}{*}{$\begin{array}{l}\text { angular } \\
\text { momentum } \\
\text { and parity }\end{array}$} & \multicolumn{2}{|c|}{ energy } & \multirow{2}{*}{$\begin{array}{l}\text { exptl }{ }^{11} \text { energy } \\
\left(\mathrm{cm}^{-1}\right)\end{array}$} \\
\hline & & $(\mathrm{eV})$ & $\left(\mathrm{cm}^{-1}\right)$ & \\
\hline \multirow[t]{4}{*}{ V } & $3 / 2+$ & 0.0 & 0.0 & 0.0 \\
\hline & $5 / 2+$ & 0.0161 & 129.85 & 137.38 \\
\hline & $7 / 2+$ & 0.0386 & 311.31 & 323.42 \\
\hline & $9 / 2+$ & 0.0665 & 536.32 & 553.02 \\
\hline \multirow[t]{4}{*}{$\mathrm{Nb}$} & $3 / 2+$ & 0.0 & 0.0 & 0.0 \\
\hline & $5 / 2+$ & 0.0525 & 423.41 & 444.11 \\
\hline & $7 / 2+$ & 0.1204 & 971.03 & 1011.32 \\
\hline & $9 / 2+$ & 0.1965 & 1584.77 & 1662.57 \\
\hline \multirow[t]{4}{*}{$\mathrm{Ta}$} & $3 / 2+$ & 0.0 & 0.0 & 0.0 \\
\hline & $5 / 2+$ & 0.2034 & 1640.42 & 2010.10 \\
\hline & $7 / 2+$ & 0.4255 & 3431.66 & 3963.92 \\
\hline & $9 / 2+$ & 0.6399 & 5160.79 & 5621.04 \\
\hline \multirow[t]{4}{*}{$\mathrm{Ha}$} & $3 / 2+$ & 0.0 & 0.0 & 0.0 \\
\hline & $5 / 2+$ & 0.4571 & 3686.71 & $(4746.25)$ \\
\hline & $7 / 2+$ & 0.8264 & 6665.28 & $(8149.68)$ \\
\hline & $9 / 2+$ & 1.0966 & 8844.56 & (10011.08) \\
\hline
\end{tabular}

a For $\mathrm{Ha}$ the data are normalized and extrapolated to the experimental values for $\mathrm{V}, \mathrm{Nb}$, and $\mathrm{Ta}$.

Results of the present MCDF computations and the thermodynamic data calculated from them are presented in the next sections.

\section{Results of the MCDF Calculations}

The MCDF calculations ${ }^{5 b}$ have shown the ground-state electronic configuration of $\mathrm{Ha}$ to be $\mathrm{d}^{3} \mathrm{~s}^{2}\left({ }^{4} \mathrm{~F}\right)$. The present calculations show that the next excited states are $\mathrm{d}^{3} \mathrm{sp}\left({ }^{6} \mathrm{G}\right)$ and $\mathrm{d}^{4} \mathrm{~s}^{1}\left({ }^{6} \mathrm{D}\right)$, lying at $1.9( \pm 0.4)$ and $2.0( \pm 0.4) \mathrm{eV}$ higher in energy, respectively. The energies of the lowest energy states that are dominated by the $d^{3} s^{2}\left({ }^{4} F\right), d^{3} s p\left({ }^{6} G\right)$, and $d^{4} s^{1}\left({ }^{6} D\right)$ configurations as a function of the total angular momentum quantum number $J$ for hahnium along with its group- 5 analogs are presented in Tables 1-3.

Since the MCDF method does not give the excitation energies as accurately as desired (mainly due to the influence of the core polarization, which cannot be taken into account by the program), the accuracy of the results has been increased by using an extrapolation procedure to obtain "experimental" energies. The extrapolation procedure used is based on ideas from the finite difference method in numerical analysis ${ }^{12}$ and is described in 
TABLE 2: Calculated Relative Energy Eigenvalues for the Lowest Energy States That Is Dominated by the $d^{4} s\left({ }^{6} D\right)$ Configuration as a Function of Total Angular Momentum $J$ for $\mathrm{V}, \mathrm{Nb}, \mathrm{Ta}$, and $\mathrm{Ha}$

\begin{tabular}{|c|c|c|c|c|}
\hline \multirow[b]{2}{*}{ element } & \multirow{2}{*}{$\begin{array}{l}\text { angular } \\
\text { momentum } \\
\text { and parity }\end{array}$} & \multicolumn{2}{|c|}{ energy } & \multirow{2}{*}{$\begin{array}{l}\text { exptl }{ }^{11} \text { energy }{ }^{a} \\
\left(\mathrm{~cm}^{-1}\right)\end{array}$} \\
\hline & & $(\mathrm{eV})$ & $\left(\mathrm{cm}^{-1}\right)$ & \\
\hline \multirow[t]{5}{*}{ V } & $1 / 2+$ & 0.0 & 0.0 & 0.0 \\
\hline & $3 / 2+$ & 0.0053 & 42.67 & 40.88 \\
\hline & $5 / 2+$ & 0.0140 & 112.92 & 107.81 \\
\hline & $7 / 2+$ & 0.0253 & 204.23 & 199.24 \\
\hline & $9 / 2+$ & 0.0369 & 297.86 & 312.57 \\
\hline \multirow[t]{5}{*}{$\mathrm{Nb}$} & $1 / 2+$ & 0.0 & 0.0 & 0.0 \\
\hline & $3 / 2+$ & 0.0163 & 131.47 & 154.19 \\
\hline & $5 / 2-$ & 0.0423 & 341.17 & 391.99 \\
\hline & $7 / 2-$ & 0.0763 & 615.39 & 695.25 \\
\hline & $9 / 2+$ & 0.1148 & 925.91 & 1050.26 \\
\hline \multirow[t]{5}{*}{$\mathrm{Ta}$} & $1 / 2+$ & 0.0 & 0.0 & 0.0 \\
\hline & $3 / 2$ & 0.0311 & 250.84 & 216.84 \\
\hline & $5 / 2+$ & 0.1361 & 1097.71 & 1484.66 \\
\hline & $7 / 2+$ & 0.2301 & 1855.86 & 2475.79 \\
\hline & & 0.3585 & 2891.46 & 3592.48 \\
\hline \multirow[t]{5}{*}{$\mathrm{Ha}$} & $1 / 2+$ & 0.0 & 0.0 & 0.0 \\
\hline & $3 / 2+$ & 0.1480 & 1193.68 & $(1022.64)$ \\
\hline & $5 / 2+$ & 0.3530 & 2847.10 & $(3851.03)$ \\
\hline & $7 / 2+$ & 0.5510 & 4444.06 & $(6060.04)$ \\
\hline & $9 / 2+$ & 0.7330 & 5911.97 & $(7656.90)$ \\
\hline
\end{tabular}

a The data for $\mathrm{Ha}$ are extrapolated and normalized to the experimental data for $\mathrm{V}, \mathrm{Nb}$, and $\mathrm{Ta}$.

TABLE 3: Calculated Relative Energy Eigenvalues for the Lowest Energy State That Is Dominated by the $d^{3} s p\left({ }^{6} G\right)$ Configuration as a Function of Total Angular Momentum $J$ for $\mathrm{V}, \mathrm{Nb}, \mathrm{Ta}$, and $\mathrm{Ha}$

\begin{tabular}{|c|c|c|c|c|}
\hline \multirow[b]{2}{*}{ element } & \multirow{2}{*}{$\begin{array}{l}\text { angular } \\
\text { momentum } \\
\text { and parity }\end{array}$} & \multicolumn{2}{|c|}{ energy } & \multirow{2}{*}{$\begin{array}{c}\text { expt1 }{ }^{11} \text { energy } \\
\left(\mathrm{cm}^{-1}\right)\end{array}$} \\
\hline & & $(\mathrm{eV})$ & $\left(\mathrm{cm}^{-1}\right)$ & \\
\hline \multirow[t]{6}{*}{ V } & $3 / 2$ & 0.0 & 0.0 & 0.0 \\
\hline & & 0.0102 & 82.26 & 88.40 \\
\hline & $7 / 2-$ & 0.0245 & 197.93 & 211.09 \\
\hline & $9 / 2-$ & 0.0429 & 345.99 & 367.30 \\
\hline & $11 / 2-$ & 0.0654 & 527.45 & 555.70 \\
\hline & $13 / 2-$ & 0.0920 & 741.98 & 774.99 \\
\hline \multirow[t]{6}{*}{$\mathrm{Nb}$} & $3 / 2-$ & 0.0 & 0.0 & 0.0 \\
\hline & $5 / 2-$ & 0.0353 & 284.69 & 309.01 \\
\hline & & 0.0837 & 675.04 & 631.96 \\
\hline & $9 / 2$ & 0.1448 & 1167.81 & 1265.26 \\
\hline & $11 / 2-$ & 0.2176 & 1754.94 & 1763.14 \\
\hline & $13 / 2-$ & 0.3015 & 2431.59 & 2204.46 \\
\hline \multirow[t]{6}{*}{$\mathrm{Ta}$} & $3 / 2-$ & 0.0 & 0.0 & 0.0 \\
\hline & $5 / 2-$ & 0.1450 & 1169.43 & 1793.80 \\
\hline & $7 / 2-$ & 0.3396 & 2738.87 & 3175.61 \\
\hline & $9 / 2-$ & 0.5705 & 4601.08 & 5297.06 \\
\hline & $11 / 2$ & 0.8378 & 6756.86 & 7624.18 \\
\hline & $13 / 2-$ & 1.1521 & 9291.69 & \\
\hline \multirow[t]{6}{*}{$\mathrm{Ha}$} & $3 / 2-$ & 0.0 & 0.0 & 0.0 \\
\hline & $5 / 2-$ & 0.3730 & 3008.25 & $(4814.81)$ \\
\hline & $7 / 2-$ & 0.7360 & 5935.84 & $(7386.73)$ \\
\hline & $9 / 2-$ & 0.9440 & 7613.36 & $(9429.60)$ \\
\hline & $11 / 2-$ & 1.4440 & 11645.86 & $(14250.86)$ \\
\hline & $13 / 2-$ & 2.6540 & 21404.50 & \\
\hline
\end{tabular}

a For $\mathrm{Ha}$ the data are normalized and extrapolated to the experimental values for $\mathrm{V}, \mathrm{Nb}$, and $\mathrm{Ta}$.

application to elements 104 and 105 in refs $5 a, b$. The uncertainty in the ionization potentials presented there is less than $0.3 \mathrm{eV}$. These experimental values, shown in Tables $1-3$ in the parentheses, can be used for calculations of the thermodynamic functions and predictions of chemical properties.

A general trend in the group is an increase in energies (more negative) of the excited states in going from $\mathrm{V}$ to $\mathrm{Ha}$. The first fine-structure level $(J=5 / 2)$ for $\mathrm{Ha}\left(\mathrm{d}^{3} \mathrm{~s}^{2}\right)$ has an energy which is nearly enough to bring Ta to the next excited state $\left({ }^{4} \mathrm{P}\right)$. Thus, much higher temperatures are needed to make the excited states of Ha occupied in comparison with the analogs.

\section{Thermodynamic Functions and Sources of Data}

A model of a monatomic ideal gas was used to calculate the entropy, enthalpy, and free energy of hahnium. The expression for the translational entropy of an ideal gas is

$$
S=N_{0} k\left[\ln \left(\frac{Z(2 \pi m k T)^{3 / 2} k T}{h^{3} P}\right)+\frac{5}{2}\right]
$$

Here $N_{0}=6.022 \times 10^{23} \mathrm{~mol}^{-1}, k=1.380 \times 10^{-23} \mathrm{~J} \times \mathrm{K}^{-1}, P=$ $1 \mathrm{~atm}=1.01325 \times 10^{6} \mathrm{dyne} \mathrm{cm}^{-1} ; m$ is the mass of $\mathrm{Ha}$ equal to $266 / N_{0}$, and $h=6.626 \times 10^{-34} \mathrm{~J} \mathrm{~s}$. The calculation of this function, as well as of the free energy, for an ideal gas requires a calculation of the specific form of the partition function $Z$, i.e.

$$
Z_{i}=\sum_{k} g_{k} \mathrm{e}^{-\Delta \epsilon_{k} / T}=\sum_{J}(2 J+1) \mathrm{e}^{-\Delta \epsilon_{j} / T}
$$

Here $g_{k}$ is a statistical weight for electron states (or degree of degeneracy of a level) equal to $2 J+1$, and $\Delta \epsilon_{J}$ is the difference between energies of the fine-structure components for a given term of the element. The summation is taken over all possible values of the total angular momentum $J$ for all $\mathrm{L}$ and $\mathrm{S}$ states.

Considering the monatomic gas in a temperature interval between 273 and $4000 \mathrm{~K}$, we make here the following comment. As the gas temperatures increase, the number of atoms in excited states also increases with some of them even being ionized. When the temperatures are not too high $\left(T \ll I_{\text {ion }}\right)$, the relative number of ionized atoms in the gas phase is negligible, but the gas is nearly fully ionized at temperatures of the order of the ionization energy and not only at $T \gg I_{\text {ion }} \cdot{ }^{13}$ Thus, a nonionized gas can be considered at temperatures $T \ll I_{\text {ion }}$.

In many atoms the energy difference between the ground state (term) and the first excited state (next term) is comparable with the ionization energy. At temperatures $T \ll I_{\text {ion }}$, the gas will therefore be practically free not only of ionized atoms but also of excited atoms, so all the atoms may be regardered as being in the ground state.

The temperatures (below $5000 \mathrm{~K}$ ), for which the thermodynamic data are presented, are below the boiling point of $\mathrm{Ha}$ (for comparison, $T_{\mathrm{b}}$ of $\mathrm{Nb}$ is $5200 \mathrm{~K}$ and $T_{\mathrm{b}}$ of $\mathrm{Ta}$ is $5702 \mathrm{~K}$ ). Thus, at the temperatures below $5000 \mathrm{~K} \mathrm{Ha}$ will be in the lowest energy state ${ }^{4} \mathrm{~F}$ of the electronic configuration $\mathrm{d}^{3} \mathrm{~s}^{2}$. The partition function $Z$ in this case can be very well calculated only for the ${ }^{4} \mathrm{~F}$ state using the fine-structure energy levels from Table 1 . The next ionized state of the $\mathrm{d}^{3} \mathrm{~s}^{2}$ configuration, probably, ${ }^{4} \mathrm{P}$, will be at energies higher than $10011.08 \mathrm{~cm}^{-1}$ (the highest level of the ${ }^{4} \mathrm{~F}$ term). Taking this value as a limit, we calculated a value of $Z$ for the ${ }^{4} \mathrm{P}$ term at $4000 \mathrm{~K}$. This correction to the value of $Z$ obtained only for the ${ }^{4} \mathrm{~F}$ term is 0.03 . Thus, within the temperatures between 273 and $4000 \mathrm{~K}$ we can restrict ourselves to consideration of only the ${ }^{4} \mathrm{~F}$ term. With the energy differences $\Delta \epsilon_{J}$ from Table 1, the expression for the partition function of $\mathrm{Ha}$ in the electronic configuration $\mathrm{d}^{3} \mathrm{~s}^{2}$ as a function of temperature is

$$
Z\left(\mathrm{Ha}, \mathrm{d}^{3} \mathrm{~s}^{2}\right)=4+6 \mathrm{e}^{-4746 / T}+8 \mathrm{e}^{-8149 / T}+10 \mathrm{e}^{-10011 / T}
$$

The values of $Z$ obtained for the $d^{3} s^{2}$ configuration and corresponding values of the entropy are given in Table 4 .

We have also calculated the partition function and entropy for the next excited-state electronic configurations $d^{3} \operatorname{sp}\left({ }^{6} G\right)$ and $\mathrm{d}^{4} \mathrm{~s}\left({ }^{6} \mathrm{D}\right)$, assuming the gas was previously ionized. Substitution of $\Delta \epsilon J$ in eq 2 by their values from Tables 2 and 3 gives the following expressions for the partition function:

$$
\begin{array}{r}
Z\left(\mathrm{Ha}, \mathrm{d}^{3} \mathrm{sp}\right)=4+6 \mathrm{e}^{-4815 / T}+8 \mathrm{e}^{-7387 / T}+10 \mathrm{e}^{-9429 / T}+ \\
12 \mathrm{e}^{-14251 / T}+14 \mathrm{e}^{-21404 / T} \\
Z\left(\mathrm{Ha}, \mathrm{d}^{4} \mathrm{~s}^{1}\right)=2+4 \mathrm{e}^{-1023 / T}+6 \mathrm{e}^{-3851 / T}+8 \mathrm{e}^{-6060 / T}+ \\
10 \mathrm{e}^{-7657 / T}
\end{array}
$$

where $T$ is measured in $\mathrm{cm}^{-1}$. 
TABLE 4: Calculated Electron Partition Function $Z$ and the Entropy $\boldsymbol{S}$ for Element 105 in Electronic Configuration $d^{3} s^{2}\left({ }^{4} F\right)$

\begin{tabular}{llccc}
\hline & \multicolumn{5}{c}{$T$} & & \\
\cline { 1 - 2 }$(\mathrm{K})$ & $\left(\mathrm{cm}^{-1}\right)$ & $Z$ & $\ln Z$ & $S\left(\mathrm{~J} \mathrm{~mol}^{-1} \mathrm{~K}^{-1}\right)$ \\
\hline 273 & 189 & 4.000 & 1.386 & 188.05 \\
298 & 206 & 4.000 & 1.386 & 189.90 \\
323 & 224 & 4.000 & 1.386 & 191.56 \\
373 & 259 & 4.000 & 1.386 & 194.54 \\
423 & 293 & 4.000 & 1.386 & 197.17 \\
500 & 346 & 4.000 & 1.386 & 200.63 \\
750 & 519 & 4.003 & 1.387 & 209.08 \\
1000 & 695 & 4.006 & 1.387 & 215.05 \\
1500 & 1038 & 4.065 & 1.402 & 223.61 \\
2000 & 1390 & 4.200 & 1.435 & 229.86 \\
2500 & 1731 & 4.460 & 1.495 & 234.99 \\
3000 & 2085 & 4.856 & 1.580 & 239.49 \\
3500 & 2423 & 5.288 & 1.666 & 243.40 \\
4000 & 2780 & 5.788 & 1.756 & 246.93 \\
$T \gg \Delta \epsilon_{J}$ & $T \gg \Delta \epsilon_{J}$ & 28 & 3.332 & $>286.78$
\end{tabular}

TABLE 5: Calculated Electron Partition Function $Z$ and the Entropy $S$ for Element 105 in Electronic Configuration $d^{3} \mathbf{s p}\left({ }^{6} \mathbf{G}\right)$

\begin{tabular}{llllc}
\hline & $T$ & & & \\
\cline { 1 - 2 }$(\mathrm{K})$ & $\left(\mathrm{cm}^{-1}\right)$ & $Z$ & $\ln Z$ & $S\left(\mathrm{~J} \mathrm{~mol}^{-1} \mathrm{~K}^{-1}\right)$ \\
\hline 273 & 189 & 4.000 & 1.386 & 188.05 \\
298 & 206 & 4.000 & 1.386 & 189.90 \\
323 & 224 & 4.000 & 1.386 & 191.56 \\
373 & 259 & 4.000 & 1.386 & 194.54 \\
423 & 293 & 4.000 & 1.386 & 197.17 \\
500 & 346 & 4.000 & 1.386 & 200.63 \\
750 & 519 & 4.003 & 1.387 & 209.08 \\
1000 & 695 & 4.006 & 1.387 & 215.05 \\
1500 & 1038 & 4.065 & 1.402 & 223.61 \\
2000 & 1390 & 4.239 & 1.444 & 229.91 \\
2500 & 1731 & 4.530 & 1.511 & 235.14 \\
3000 & 2085 & 4.949 & 1.599 & 239.66 \\
3500 & 2423 & 5.441 & 1.694 & 243.65 \\
4000 & 2780 & 6.039 & 1.798 & 247.30 \\
$T \gg \Delta \epsilon_{J}$ & $T \gg \Delta \epsilon_{J}$ & 30 & 3.401 & $>281.74$
\end{tabular}

TABLE 6: Calculated Electron Partition Function $Z$ and the Entropy $S$ for Element 105 in Electronic Configuration $d^{4} s^{1}\left({ }^{6} D\right)$

\begin{tabular}{clccc}
\hline & $T$ & & & \\
\cline { 1 - 2 }$(\mathrm{K})$ & $\left(\mathrm{cm}^{-1}\right)$ & & $\ln Z$ & $S\left(\mathrm{~J} \mathrm{~mol}^{-1} \mathrm{~K}^{-1}\right)$ \\
\hline 273 & 189 & 2.016 & 0.701 & 182.36 \\
298 & 206 & 2.028 & 0.707 & 184.23 \\
323 & 224 & 2.041 & 0.714 & 185.98 \\
373 & 259 & 2.077 & 0.731 & 189.09 \\
423 & 293 & 2.122 & 0.752 & 191.90 \\
500 & 346 & 2.207 & 0.792 & 195.69 \\
750 & 519 & 2.557 & 0.939 & 205.36 \\
1000 & 695 & 2.943 & 1.079 & 212.42 \\
1500 & 1038 & 3.677 & 1.302 & 222.77 \\
2000 & 1390 & 4.388 & 1.479 & 230.22 \\
2500 & 1731 & 5.230 & 1.655 & 236.32 \\
3000 & 2085 & 6.088 & 1.806 & 241.37 \\
3500 & 2423 & 6.933 & 1.936 & 245.66 \\
4000 & 2780 & 7.805 & 2.055 & 249.42 \\
$T \gg \Delta \epsilon_{J}$ & $T \gg \Delta \epsilon_{J}$ & 54 & 3.959 & $>310.82$
\end{tabular}

The values obtained for $Z$ and corresponding values of the entropy for $P=1 \mathrm{~atm}$ are presented in Tables 5 and 6 .

For the heavy-metal vapors, sometimes in practice a range of high temperatures is of importance, so that the temperature is large in comparison with the fine-structure intervals, $T \gg \Delta \epsilon_{J}$. In this case, one can put $\mathrm{e}^{-\Delta t_{j} / T} \simeq 1$ in expression 2 , and $Z$ becomes simply the total number of the fine-structure components $(2 \mathrm{~S}+$ 1) $(2 \mathrm{~L}+1)$. In this case the value of specific heat becomes constant $\left(C_{v}=3 / 2\right)$ (see ref 12). Thus, at $T \gg \Delta \epsilon_{J}$, the values of $Z$ for Ha in electronic configurations $\mathrm{d}^{3} \mathrm{~s}^{2}, \mathrm{~d}^{3} \mathrm{sp}$, and $\mathrm{d}^{4} \mathrm{~s}$ are 28,30 , and
TABLE 7: Calculated Values of the Free Energy, $G$, and the Enthalpy, $H$, for Element 105 in Electronic Configuration $d^{3} s^{2}\left({ }^{4} F\right)$

\begin{tabular}{rccc}
\hline$T(\mathrm{~K})$ & $T S\left(\mathrm{~kJ} \mathrm{~mol}^{-1}\right)$ & $-G\left(\mathrm{~kJ} \mathrm{~mol}^{-1}\right)$ & $H\left(\mathrm{~kJ} \mathrm{~mol}^{-1}\right)$ \\
\hline 273 & 51.338 & 45.664 & 5.673 \\
298 & 56.582 & 50.388 & 6.194 \\
323 & 61.873 & 55.159 & 6.714 \\
373 & 72.564 & 64.811 & 7.753 \\
423 & 83.402 & 74.610 & 8.792 \\
500 & 100.315 & 89.922 & 10.393 \\
750 & 156.810 & 141.220 & 15.590 \\
1000 & 215.053 & 194.267 & 20.786 \\
1500 & 335.408 & 304.229 & 31.179 \\
2000 & 459.713 & 418.140 & 41.572 \\
2500 & 587.475 & 535.510 & 51.965 \\
3000 & 718.464 & 656.106 & 62.358 \\
3500 & 851.913 & 779.161 & 72.751 \\
4000 & 987.725 & 904.581 & 83.144
\end{tabular}

TABLE 8: Calculated Values of the Free Energy, $G$, and the Enthalpy, $\boldsymbol{H}$, for Element 105 in Electronic Configuration $d^{3} \operatorname{sp}\left({ }^{6} G\right)$

\begin{tabular}{rccc}
\hline$T(\mathrm{~K})$ & $T S\left(\mathrm{~kJ} \mathrm{~mol}^{-1}\right)$ & $-G\left(\mathrm{~kJ} \mathrm{~mol}^{-1}\right)$ & $H\left(\mathrm{~kJ} \mathrm{~mol}^{-1}\right)$ \\
\hline 273 & 51.338 & 45.664 & 5.673 \\
298 & 56.582 & 50.388 & 6.194 \\
323 & 61.873 & 55.159 & 6.714 \\
373 & 72.564 & 64.811 & 7.753 \\
423 & 83.402 & 74.610 & 8.792 \\
500 & 100.315 & 89.922 & 10.393 \\
750 & 156.810 & 141.220 & 15.590 \\
1000 & 215.053 & 194.267 & 20.786 \\
1500 & 335.408 & 304.229 & 31.179 \\
2000 & 459.820 & 418.320 & 41.500 \\
2500 & 587.850 & 535.885 & 51.965 \\
3000 & 718.980 & 656.634 & 62.346 \\
3500 & 852.775 & 780.052 & 72.723 \\
4000 & 989.200 & 906.048 & 83.152
\end{tabular}

TABLE 9: Calculated Values of the Free Energy, $G$, and the Enthalpy, $H$, for Element 105 in Electronic Configuration $\mathrm{d}^{4} \mathbf{s}^{1}\left({ }^{6} \mathrm{D}\right)$

\begin{tabular}{rrrr}
\hline$T(\mathrm{~K})$ & $T S\left(\mathrm{~kJ} \mathrm{~mol}^{-1}\right)$ & $-G\left(\mathrm{~kJ} \mathrm{~mol}^{-1}\right)$ & $H\left(\mathrm{~kJ} \mathrm{~mol}^{-1}\right)$ \\
\hline 273 & 49.781 & 44.107 & 5.673 \\
298 & 54.898 & 48.706 & 6.194 \\
323 & 60.071 & 53.357 & 6.714 \\
373 & 70.529 & 62.776 & 7.753 \\
423 & 81.542 & 72.749 & 8.792 \\
500 & 97.843 & 87.449 & 10.393 \\
750 & 154.020 & 138.430 & 15.590 \\
1000 & 212.488 & 191.703 & 20.786 \\
1500 & 334.151 & 302.972 & 31.179 \\
2000 & 460.441 & 418.868 & 41.572 \\
2500 & 590.802 & 538.836 & 51.965 \\
3000 & 724.112 & 661.754 & 62.358 \\
3500 & 859.808 & 787.056 & 72.751 \\
4000 & 997.666 & 914.521 & 83.144
\end{tabular}

54 , respectively. The corresponding values of the entropy are presented in Tables 4-6.

The free energy for element 105 has been calculated using the formula

$$
G=-N_{0} k T\left[\ln \left(\frac{Z(2 \pi m k T)^{3 / 2} k T}{h^{3} P}\right)\right]
$$

The calculated $G$ 's for $\mathrm{Ha}\left(\mathrm{d}^{3} \mathrm{~s}^{2}\right), \mathrm{Ha}\left(\mathrm{d}^{3} \mathrm{sp}\right)$, and $\mathrm{Ha}\left(\mathrm{d}^{4} \mathrm{~s}^{1}\right)$ as a function of temperature are given in Tables 7-9.

The enthalpy, $H$, can be calculated from the general expression

$$
G=H-T S
$$

The values obtained for $H$ for the Ha states under discussion are also presented in Tables 7-9.

A $\mathrm{Ha}^{5+}$ ionized state was also included in the present consideration. For the $5 \mathrm{f}^{14}$ electronic configuration the value of 
TABLE 10: Calculated Values of the Entropy, $S$, the Free Energy, $G$, and the Enthalpy, $H$, for $\mathrm{Ha}^{5+}\left(5 \mathrm{f}^{14}\right)^{a}$

\begin{tabular}{|c|c|c|c|c|c|}
\hline \multicolumn{2}{|c|}{$T$} & \multirow{2}{*}{$\underset{\left(\mathrm{J} \mathrm{mol}^{-1} \mathrm{~K}^{-1}\right)}{S}$} & \multirow{2}{*}{$\begin{array}{c}T S \\
\left(\mathrm{~kJ} \mathrm{~mol}^{-1}\right)\end{array}$} & \multirow{2}{*}{$\begin{array}{c}-G \\
(\mathrm{~kJ} \mathrm{~mol} \\
\end{array}$} & \multirow{2}{*}{$\begin{array}{c}H \\
\left(\mathrm{~kJ} \mathrm{~mol}^{-1}\right)\end{array}$} \\
\hline$(\mathrm{K})$ & $\left(\mathrm{cm}^{-1}\right)$ & & & & \\
\hline 273 & 189 & 176.53 & 48.191 & 42.517 & 5.673 \\
\hline 298 & 206 & 178.38 & 53.182 & 46.982 & 6.205 \\
\hline 323 & 224 & 180.04 & 58.153 & 51.439 & 6.714 \\
\hline 373 & 259 & 183.02 & 62.266 & 60.513 & 5.523 \\
\hline 423 & 293 & 185.65 & 78.529 & 69.736 & 8.793 \\
\hline 500 & 346 & 189.13 & 94.562 & 84.169 & 10.393 \\
\hline 750 & 519 & 197.55 & 148.162 & 132.586 & 15.576 \\
\hline 1000 & 695 & 203.53 & 203.535 & 182.748 & 20.781 \\
\hline 1500 & 1038 & 211.96 & 317.942 & 286.759 & 31.179 \\
\hline 2000 & 1390 & 217.94 & 435.889 & 394.275 & 41.618 \\
\hline 2500 & 1731 & 222.58 & 556.451 & 504.485 & 51.965 \\
\hline 3000 & 2085 & 226.37 & 679.113 & 616.725 & 62.387 \\
\hline 3500 & 2423 & 229.56 & 803.445 & 730.689 & 72.751 \\
\hline 4000 & 2780 & 232.33 & 929.316 & 846.172 & 83.144 \\
\hline
\end{tabular}

${ }^{a}$ For $\mathrm{Ha}^{5+}\left(5 \mathrm{f}^{14}\right), Z=1$.

TABLE 11: Approximate Solid-State Electronic

Configurations of the Transition Metals of Groups 4-7

\begin{tabular}{|c|c|c|c|}
\hline group 4 & group 5 & group 6 & group 7 \\
\hline $\begin{array}{c}\mathrm{Ti} \\
\mathrm{d}^{3-x} \mathrm{sp}^{x}\end{array}$ & $\begin{array}{c}\mathrm{V} \\
\mathrm{d}^{4} \mathrm{~s}\end{array}$ & $\begin{array}{l}\mathrm{Cr} \\
\mathrm{d}^{5} \mathrm{~s}\end{array}$ & $\begin{array}{c}M n \\
d^{6} s+d^{5} s p\end{array}$ \\
\hline$\underset{\mathrm{d}^{3-x} \mathrm{sp}^{x}}{\mathrm{Zr}}$ & $\begin{array}{l}\mathrm{Nb} \\
\mathrm{d}^{4} \mathrm{~s}\end{array}$ & $\begin{array}{l}\text { Mo } \\
d^{5} s\end{array}$ & $\underset{\mathrm{d}^{6-x} \mathrm{sp}^{x}}{\mathrm{Tc}}$ \\
\hline$\underset{d^{3-x} s p^{x}}{H f}$ & $\underset{d^{4-x} s p^{x}}{T a}$ & $\begin{array}{l}W \\
d^{5} s\end{array}$ & $\underset{d^{6-x} s p^{x}}{\operatorname{Re}}$ \\
\hline $\begin{array}{c}104 \\
\mathrm{~d}^{3-x} \mathrm{sp}^{x}\end{array}$ & $\begin{array}{c}105 \\
d^{4-x} s p^{x}\end{array}$ & $\begin{array}{l}106 \\
d^{5} s\end{array}$ & $\begin{array}{c}107 \\
d^{6-x} s p^{x}\end{array}$ \\
\hline
\end{tabular}

$Z$ is equal to unity. The calculated thermodynamic values for $\mathrm{Ha}^{5+}$ are presented in Table 10.

The values of the partition function can also be used for calculating some other physicochemical characteristics such as, for example, chemical potentials. The latter can be used for calculations of a partial pressure of the gaseous element.

\section{Sublimation Enthalpies of the Metals}

A. Electronic Structure of the Transition Metals. It was shown ${ }^{14}$ that the highly directional properties of the d-electrons determine the crystal structure for transition metals. The following correlation has been accepted for the transition metals (see Table 11):

1. For metals which are likely to have electronic configuration $\mathrm{d}^{x}(0<x<2)$, the crystal lattice has the fcc structure.

2. For metals with $d^{5}$ configuration (at or near it), the crystal structure is bcc.

3. For metals with intermediate configurations $\mathrm{d}^{x}(2<x<$ 4), the crystal lattice is hcp.

$\mathrm{V}, \mathrm{Nb}, \mathrm{Ta}$, and $\mathrm{Ha}$ belong to the third class. It means that the lattice may change the symmetry from bcc to hcp depending on the temperature.

Our molecular orbital calculations ${ }^{7}$ of hahnium compounds show that there is some electron population of the $7 p_{1 / 2}$ orbitals of Ha. Analogously, we can assume that in the metallic hahnium as well as in metallic elements 106-111 the $n$ p electrons are available.

Metals of group 4 have $\mathrm{d}^{3-x} \mathrm{sp}^{x}$ configuration with $x$ approximately equal for $\mathrm{Ti}$ and $\mathrm{Zr}$ and much larger for $\mathrm{Hf}$. The presence of the p-electrons in the electronic configuration of $\mathrm{Hf}$ stabilizes the hcp structure. Hf transforms to the high-temperature bcc state at a very high temperature. Apparently, element 104 will be preferentially in the hep structure too. But if consideration is taken of the fact that in the ground state the $7 p$ orbitals of element 104 have a large electron population, ${ }^{15,16}$ the $\mathrm{hcp} \rightarrow \mathrm{fcc}$ transformation is to be expected at higher temperatures.

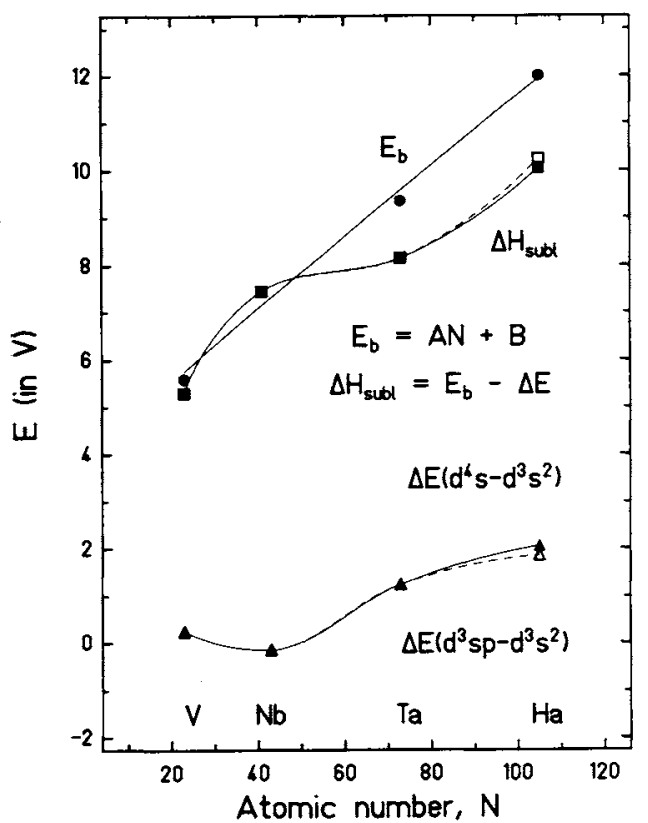

Figure 1. Sublimation energy of a metal $\Delta H_{\text {subl, }}$, cohesive energy $E_{\mathrm{c}}$, and the difference between energies of electronic configurations in the gas phase and in the solid state $\Delta E\left(\mathrm{~d}^{4} \mathrm{~s}-\mathrm{d}^{3} \mathrm{~s}^{2}\right)$ (filled triangles) and $\Delta E\left(\mathrm{~d}^{3} \mathrm{sp}-\right.$ $\mathrm{d}^{3} \mathrm{~s}^{2}$ ) (open triangle for $\mathrm{Ha}$ ) as a function of the atomic number. A filled square is $\Delta H_{\text {subl }}$ of $\mathrm{Ha}$ for the electronic configuration $\mathrm{d}^{4} \mathrm{~s}$ in the metal, and an open square is $\Delta H_{\text {subl }}$ for the $\mathrm{d}^{3} \mathrm{sp}$ electronic configuration.

In group $5, \mathrm{Ta}$ and $\mathrm{Ha}$ can be considered a borderline case on the bcc side of the border.

In group 6 the p-valence electrons are high in energy owing to a strong orbital effect in the half-occupied $d^{5}$ shell. This requires a bcc structure.

For metallic Tc and Re a larger population of the p-atomic orbitals was accepted ${ }^{14}$ in comparison with $\mathrm{Nb}$ and $\mathrm{Ta}$, and the $\mathrm{d}^{6-x} \mathrm{Sp}^{x}$ configuration was considered as an equivalent to the $\mathrm{d}^{4+x} \mathrm{sp}^{x}$ one. This would stabilize the hcp structure in all three metals of the group (Tc, Re, and element 107), with the effect being more pronounced in the case of element 107 due to strong relativistic effects.

B. Sublimation Enthalpy of the Metallic Hahnium. Assuming that hahnium has the same structure in the metallic state as $\mathrm{Nb}$ or Ta having the bcc lattice, we will try to estimate its sublimation enthalpy using the results of the present MCDF calculations. The sublimation enthalpy can be expressed ${ }^{17}$ as

$$
\Delta H_{\text {subl }}=E_{\mathrm{b}}-\Delta E
$$

where $E_{\mathrm{b}}$ is the valence state bonding energy of the metal (or the cohesive energy which can be measured as the enthalpy of sublimation to a gaseous atom with the same electronic configuration as in the metal) and $\Delta E$ is the difference between the energy of the ground-state electronic configuration realized in the gas phase and the energy of the exited-state configuration realized in the condensed state. Thus we can estimate $\Delta H_{\text {subl }}$ knowing the values of $\Delta E\left(\mathrm{~d}^{4} \mathrm{~s}-\mathrm{d}^{3} \mathrm{~s}^{2}\right)$ or $\Delta E\left(\mathrm{~d}^{3} \mathrm{sp}-\mathrm{d}^{3} \mathrm{~s}^{2}\right)$, and $E_{\mathrm{b}}$.

For the lanthanides and actinides it was shown ${ }^{17,18}$ that the bonding energy $E_{\mathrm{b}}$ is a smooth function of the atomic number $N$. $E_{\mathrm{b}}$ for the group 5 elements $\mathrm{V}, \mathrm{Nb}$, and $\mathrm{Ta}$ can be determined using eq 8. There, $\Delta E=E\left(\mathrm{~d}^{4} \mathrm{~s}\right)-E\left(\mathrm{~d}^{3} \mathrm{~s}^{2}\right)$ for $\mathrm{V}, \mathrm{Nb}$, and $\mathrm{Ta}$ are experimental spectroscopic data, ${ }^{11}$ and $\Delta E=E\left(\mathrm{~d}^{4} \mathrm{~s}\right)-E\left(\mathrm{~d}^{3} \mathrm{~s}^{2}\right)=$ $2.0( \pm 0.4) \mathrm{eV}$ for $\mathrm{Ha}$ was obtained as a result of the present atomic MCDF calculations. Thus knowing $\Delta E$ values for all the elements under consideration and $\Delta H_{\text {subl }}{ }^{19}$ for $\mathrm{V}, \mathrm{Nb}$, and $\mathrm{Ta}$, we have found their $E_{\mathrm{b}}$ values. In accordance with the idea developed in ref 18 we see that $E_{\mathrm{b}}$ is a linear function of $N$ for the group 5 elements (Figure 1). Thus we can find $E_{\mathrm{b}}$ for $\mathrm{Ha}$, which together with the value of $\Delta E\left(\mathrm{~d}^{4} \mathrm{~s}-\mathrm{d}^{3} \mathrm{~s}^{2}\right)$ gives $\Delta H_{\text {subl }}=10.1 \mathrm{eV}$ or 973.54 $\mathrm{kJ} / \mathrm{mol}$. Using $\Delta E\left(\mathrm{~d}^{3} \mathrm{sp}-\mathrm{d}^{3} \mathrm{~s}^{2}\right)$ equal to $1.9( \pm 0.4) \mathrm{V}$ gives $\Delta H_{\text {subl }}$ 
$=10.2 \mathrm{eV}$. These estimated values nevertheless seem to be enhanced. Calculations of the sublimation enthalpy at the mixed $\mathrm{d}^{4-x} \mathrm{sp}^{x}$ configuration is needed to give the final value of $\Delta \mathrm{H}_{\text {subl }}$ for Ha.

Acknowledgment. V.P. would like to thank the W. E. Heraeus Stiftung for financial support. This research was cosponsored by the Division of Chemical Sciences, Office of Basic Energy Sciences, U.S. Department of Energy, under Contract DE-FC0585ER25000 with Martin Marietta Energy Systems, Inc.

\section{References and Notes}

(1) Gäggeler, H. W.; Jost, D. T.; Baltensperger, U.; Ya, N.-Q.; Gregorich, K. E.; Gannett, C. M.; Hall, H. L.; Henderson, R. A.; Lee, D. M.; Li, J. D.; Nurmia, M. J.; Hoffman, D.C.; Türler, A.; Lienert, Ch.;Schädel, M.; Brüchle, W.; Kratz, J. V.; Zimmermann, H. P.; Scherer, U. W. Report PSI, PSIBericht No. 49, 1989. Radiochim. Acta, in press.

(2) Zvara, I.; Belov, V. Z.; Chelnokov, L. B.; Domanov, V. P.; Hussonnois, M.; Korotkin, Yu. S.; Schegolev, V. A.; Shalayevskii, M. R. Inorg. Nucl. Chem. Lett. 1971, 7, 1109.

(3) Zhuikov, B. L.; Chuburkov, Yu. T.; Timokhin, S. N.; Zvara, I. Radiochim. Acta 1989, 46, 113.

(4) Hoffman, D. C. Chemistry of the Transactinide Elements. In Proceedings of the Robert A. Welch Foundation Conference on Chemical Research.XXXIV: Fifty Years with Transuranium Elements; Houston, TX, 1990; Vol. VIII, p 255 .

(5) (a) Johnson, E.; Fricke, B.; Keller, D. L., Jr.; Nestor, C. W., Jr.; Tucker, T. C. J. Chem. Phys. 1990, 93, 8041. (b) Fricke, B.; Johnson, E.
Radiochim. Acta, to be published.

(6) Glebov, V.A.; Kasztura, L.; Nefedov, V.S.;Zhuikov, B. L. Radiochim. Acta 1989, 46, 117.

(7) (a) Pershina, V.; Sepp, W.-D.; Fricke, B.; Rosen, A. J. Chem. Phys. 1992, 96, 8367. (b) Pershina, V.; Sepp, W.-D.; Fricke, B.; Kolb, D.; Schädel, M.; Ionova, G. V. J. Chem. Phys. 1992, 97, 1116 . (c) Pershina, V.; Sepp, W.-D.; Bastug, T.; Fricke, B.; Ionova, G. V.J. Chem. Phys. 1992, 97, 1123. (8) Jost, D. T.; Gäggeler, H. W.; Vogel, Ch.; Schädel, M.; Jäger, E.; Eichler, B.; Gregorich, K. E.; Hoffman, D. C. Inorg. Chim. Acta 1988, 146, 255

(9) (a) Zhuikov, B. L.; Chuburkov, Yu. T.; Timokhin, S. N.; Zvara, I. Radiochim. Acta 1989, 46, 113.

(10) Eichler, B.; Hübener, S.; Gäggeler, H. W.; Jost, D. T. Inorg. Chim. Acta 1988, 146, 261.

(11) Moore, C. E. Atomic Energy Levels; Circular of the National Bureau of Standards 476; National Bureau of Standards: Washington, D.C., 1949; Vols. I-III.

(12) Booth, A. Numerical Methods, 3rd ed.; Butterworth: London, 1966;

(13) Landau, L. D.; Lifshitz, E. M. Statistical Physics, Part 1; Permagon Press: Oxford, U.K., 1980; p 132.

(14) Pecora, L.; Ficalora, P. J. Solid State Chem. 1979, 27, 239.

(15) Glebov, V.A.; Kasztura, L.; Nefedov, V.S.; Zhuikov, B. L. Radiochim. Acta 1989, 46, 117.

(16) Johnson, E.; Fricke, B.; Keller, O. L., Jr.; Nestor, C. E.; Tucker, T. C. J. Chem. Phys. 1990, 93, 8041 .

(17) Brewer, L. J. Opt. Soc. Am. 1971, 61, 1101.

(18) Johanssen, B.; Rosengreen, A. Phys. Rev. B 1975, 11, 1367.

(19) (a) Clark, R. J. H. In Comprehensive Inorganic Chemistry, Bailar, J. C., Ed.; Pergamon Press: Oxford, U.K., 1973; Vol. 3, p 494. (b) Brown, D. In Comprehensive Inorganic Chemistry; Bailar, J. C., Ed.; Pergamon Press: Oxford, U.K., 1973; Vol. 3, p 559. 